\title{
Investigation of the effect of a gap between the cylindrical substrate and curvilinear ring on the regimes of liquid film flow
}

\author{
Anton V. Meleshkin ${ }^{1}$, Valery V. Ovchinnikov ${ }^{1, *}$, and Ruslan A. Dekhtyar ${ }^{1}$ \\ ${ }^{1}$ Kutateladze Institute of Thermophysics, 630090 Novosibirsk, Russia
}

\begin{abstract}
Experimental studies have been carried out to reveal the peculiarities of the influence of the arrangement of the curved ring on the flow regimes of a liquid film along a cylindrical surface. Regimes under which the estimated thickness of the gap between the flowing film and the cylinder may not be sufficient. Recommendations are given to determine the minimum value of the distance between the ring and the surface along which the film flows, so that at any flow of liquid there is no contact between the liquid and the ring.
\end{abstract}

\section{Introduction}

The phenomenon of physical absorption, accompanied by the release of a large amount of heat at water vapor absorption in used in the absorption heat exchangers. The use of liquid films in absorbers, condensers, and heat exchangers makes the studies of film flow structure and effect of this structure on local and average heat and mass transfer characteristics relevant [1-9]. Intensification of heat and mass transfer processes occurs both because of an increase in the film area and due to a change in the velocity profile in the film $[10,11]$. To increase the efficiency of film absorbers, it is very important to organize the uniform flow of absorbent over the heat-and-mass transfer surface without formation of dry spots and absorbent rivulets.

The aim of this work is to reveal the peculiarities of the effect of curvilinear ring arrangement on the regimes of liquid film flow along the cylindrical surface, and determine the minimal distance between the ring and the surface, where the film flows so that at any liquid flow rates there is no contact between liquid and ring.

\section{Experimental setup and methods}

Experiments were carried out at a setup, whose scheme is shown in Fig. 1a. When a circular jet from a nozzle with the diameter of $10 \mathrm{~mm}$ flowed onto a cylinder of $40 \mathrm{~mm}$ in diameter, a liquid film was formed. The distance from the nozzle cut to the cylinder surface was varied from 1 to $10 \mathrm{~mm}$. Changing the height of the nozzle cutoff location, we could

* Corresponding author: mav@itp.nsc.ru 
change the rate of jet flow onto the cylinder, at the same flow rate of liquid. The flow rate was set by means of a needle valve on the bypass line. The flow rate was previously calibrated by the rate of change in the mass of liquid in the control volume. The curvilinear ring was made of a copper wire with diameter $\mathrm{D}_{\mathrm{H}}=2 \mathrm{~mm}$ and its shape was close to the shape of the curve formed, when two cylinders of the same diameter $D_{B}$, equal to $D_{B}=D+$ $2 \cdot \mathrm{h}+\mathrm{D}_{\mathrm{H}}=46 \mathrm{~mm}$, cross (Fig. 1b). The patterns of the film flow on the cylinder were recorded by the Nikon J1 camera with the frame rate from 60 to $1000 \mathrm{fps}$. The ring was mounted to make gap $h$ one and half times higher than the maximal film thickness in the studied range of flow rates and initial velocities of water in the jet (Fig. 1c). Film thickness $\delta$ was determined for a liquid film, freely flowing along the cylinder (without a ring).

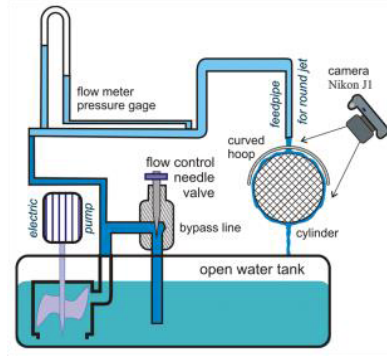

a)

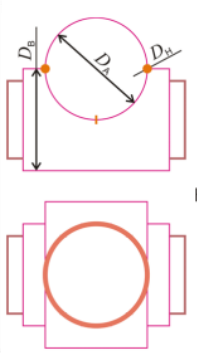

b)

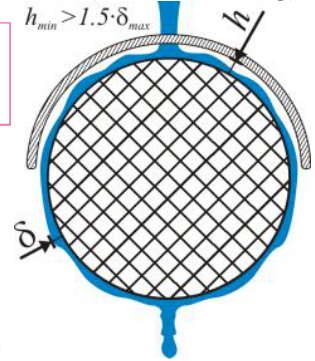

c)

Fig. 1. Scheme of setup a); ring shape b); location of ring relative to the cylinder c).

There was a series of experiments with a change in the flow rate in the jet $\mathrm{G}$ from 4 to $70 \mathrm{~g} / \mathrm{s}$ (the velocity of jet flow onto the cylinder $\mathrm{V}_{0}=0.05 \div 1.5 \mathrm{~m} / \mathrm{s}$ ). Usually the value of a minimal gap is the sum of the film thickness and maximal wave amplitude on the film surface. With a smooth change in the flow rate from the minimum to the maximum for a set gap between the ring and cylinder, the film flow regime did not change and corresponded to the regime of a freely flowing liquid film. However, the experiments have shown that at a sharp pulsation of the liquid flow (the pulsation time is less than $2 \mathrm{~s}$, more than a $50 \%$ decrease in the flow rate), a qualitative change in the liquid film pattern is possible. This is because during the transition regime, a liquid bridge is formed between the ring and liquid film (liquid bridge) and this structure is stable for a long time. An example of the liquid bridge formation and resulting change in the pattern of a liquid film flow, are shown in Fig. 2. Time reading starts from the beginning of the flow rate restoration (growth) in the incoming jet. The form and conditions for the existence of a liquid bridge between the spheres are theoretically described in [12]. The experimental results and approximation formula describing the liquid bridge shape, are given in [13]. The liquid bridge height is comparable to the Laplace constant.

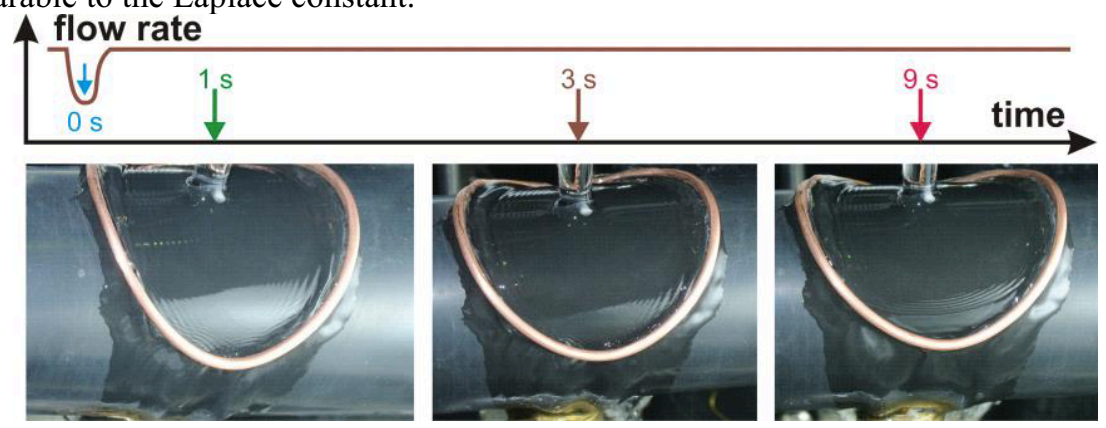

Fig. 2. Formation of a liquid bridge between the ring and liquid film after sharp flow pulsation. 
After liquid bridge formation, the character of the film flow on the cylinder starts changing. In particular, the wave patterns on the film surface vary greatly within a region limited by a curved ring. Outside this region, formation of the rolls on the film surface is observed downstream (Fig. 2). As a sequence, after formation of a liquid bridge between the ring and the liquid film, dependence between the film flow regimes on the flow rate in the incident jet changes as compared with the liquid film flowing freely along the cylinder. An example of formation of the rivulet flow regime (49s) at a smooth change in the flow rate after liquid bridge formation (10s) is shown in Fig. 3.

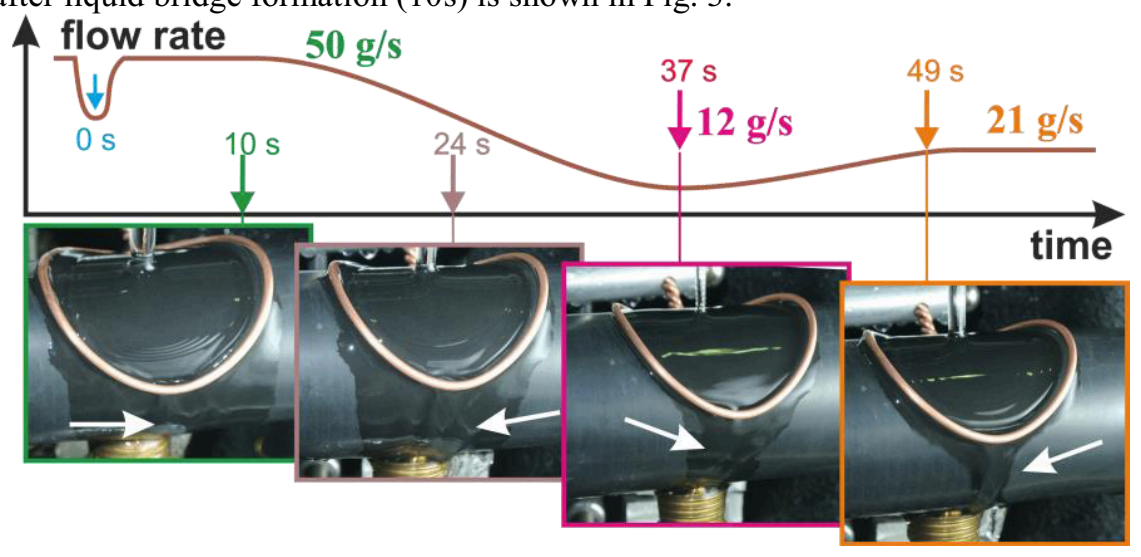

Fig. 3. Formation of a rivulet in the lower part of the cylinder after liquid bridge formation.

\section{Conclusion}

The study showed that the minimal distance at which the liquid film does not touch the outer ring is determined not only by the film thickness, but also by the height of a liquid bridge that can exist between the ring and the film. The effect of the ring on the film flow regime is determined by the fact that the ring plays the role of an indicator of nonlinear outbursts of perturbation height on the film surface. This occurs because the outbursts, short-lived on the ring surface due to the influence of wetting forces, can transform into the stable liquid elements such as liquid bridges. The existence of such structures leads to a change in the film flow patterns both inside the ring region and beyond this region downstream. As a sequence, when the liquid flow rates in the flowing jet in the lower part of the cylinder change, the film flow regime can transform into the rivulet flow.

The study was supported by the grant of the Russian Science Foundation (project No. 15-1910025).

\section{References}

1. V.E. Nakoryakov, N.S. Bufetov, R.A. Dekhtyar', J. Appl. Mech. Tech. Phys. 45 (2), 276 (2004)

2. N.S. Bufetov, R.A. Dekhtyar, N.I. Grigoryeva, V.E. Nakoryakov, J. Appl. Mech. Tech. Phys. 44 (2), 111 (2003)

3. N.S. Bufetov, R.A. Dekhtyar, N.I. Grigoryeva, V.E. Nakoryakov, I.V. Marchuk, Int. J. Heat Mass Transfer, 47 (6-7), 1525 (2004)

4. D.V. Zaitsev, O.A. Kabov, V.V. Cheverda, N.S. Bufetov, High Temp. 42 (3), 450 (2004)

5. V.E. Dontsov, A.A. Chernov, Int. J. Heat Mass Transfer, 52 (21-22), 4919 (2009) 
6. A.A. Chernov, V.E. Dontsov, Int. J. Heat Mass Transfer, 54 (19-20), 4307 (2011)

7. A.A. Chernov, A.A. Pil'nik, D.S. Elistratov, I.V. Mezentsev, A.V. Meleshkin, M.V. Bartashevich, M.G. Vlasenko, Scientific Reports, 7, 40809 (2017)

8. A.A. Chernov, D.S. Elistratov, I.V. Mezentsev, A.V. Meleshkin, A.A. Pil'nik, Int. J. Heat Mass Transfer, 108, 1320 (2017)

9. N.S. Bufetov, R.A. Dekhtyar', Polzunovsky vestnik, 1, 53 (2004)

10. S.V. Alekseenko, V.E. Nakoryakov, B.G. Pocusaev, Wave Flow of Liquid Films (Begell House, New York, 1994)

11. V.E. Nakoryakov, S.Yu. Misyura, S.L. Elistratov, J. Eng. Thermophys. 22 (1), 1 (2013)

12. S.V. Alekseenko, P.A. Kuibin. Proc. STS-XXV. 16 (1996)

13. B.V. Perepelitsa. Book of Abstracts ISHM-II, ISHM-III. 31 (2015) 